\title{
Electrospun Poly(L-Lactide-co- $\varepsilon$-Caprolactone)/Polyethylene Oxide/Hydroxyapaite Nanofibrous Membrane for Guided Bone Regeneration
}

\author{
Gang Wang, ${ }^{1}$ Tianbin Ren, ${ }^{1}$ Chunhong Cao, ${ }^{1}$ Weizhong Yuan, ${ }^{1}$ Ying Song, ${ }^{1}$ and Jiansheng Su ${ }^{2}$ \\ ${ }^{1}$ Institute of Nano and Bio-Polymeric Material, School of Material Science and Engineering, Tongji University, Shanghai, \\ 200092, China \\ ${ }^{2}$ School of Stomatology, Tongji University, Shanghai, 200092, China
}

Correspondence should be addressed to Tianbin Ren, rtb002@163.com and Jiansheng Su, ts1967118@yahoo.com.cn

Received 28 September 2009; Revised 22 November 2009; Accepted 5 March 2010

Academic Editor: Huisheng Peng

Copyright ( $) 2010$ Gang Wang et al. This is an open access article distributed under the Creative Commons Attribution License, which permits unrestricted use, distribution, and reproduction in any medium, provided the original work is properly cited.

\begin{abstract}
A series of poly(L-lactide-co-e-caprolactone)/polyethylene oxide/hydroxyapaite (PLCL/PEO/HA) composite fibrous membranes were prepared by elecrospinning technology for guided bone regeneration. The morphology, water permeability and mechanical properties of the membranes were investigated. The HA nanocrystals can be well distributed in the PLCL/PEO matrix. And the diameter of composite nanofiber is larger than that of pure PLCL. The fibers with uniform size and large diameter were obtained when the contents of PEO and HA were $0.4 \%$ and $0.03 \%$, respectively. In this condition, the obtained membrane presents the best water permeability. Furthermore, the nanofibrous membrane with largest tensile strength was obtained when the contents of PEO and HA were $0.5 \%$ and $0.03 \%$, respectively.
\end{abstract}

\section{Introduction}

Guided bone regeneration membranes (GBRMs) are able to promote bone repair for their physical barrier function, separating defects with surrounding tissues and creating necessary growth spaces to bone. Therefore, considerable attention has been paid on GBRMs for the applications in biomedical field [1-3]. The common materials of GBRMs are non-bioabsorbable materials such as expanded-polytetrafloroethylene $[4,5]$, and bioabsorbable materials such as collagen [6-10]. However, the nonbioabsorbable GBRMs have to be removed by secondary surgical procedures after new bone regeneration. In contrast, the bioabsorbable GBRMs are more and more widely researched and applied for avoiding secondary surgery to alleviate patients' sufferings and limit risks of tissue infection [11-14]. However, the natural bioabsorbable GBRMs are usually lack excellent mechanical performance and degraded rapidly which hinder bone recovery. Therefore, developing of new GBRMs composed of synthetic polymeric materials, such as polyester, or their composites with inorganic materials which have good osteoconductivity, is attracting more and more attention [1518 .

Different methods also have been developed to prepare GBRMs [19-21]. And the main technologies are solvent-casting, phase inversion, and electrospinning [2225]. Among them, nanofibrous membranes prepared by electrospinning have large specific surface area and porosity to mimic natural extracellular matrix (ECM). The thickness and pore size also can be adjusted by the control of electrospinning parameter [26-28].

In this paper, $\mathrm{PLCL} / \mathrm{PEO} / \mathrm{HA}$ composites were used to fabricate nanofibrous GBRMs by electrospinning because of their proper biodegradation rate, good biocompatibility, mechanical performance, and hydrophilic properties. The morphology, porosity, water permeability, and mechanical properties of the membranes were investigated by SEM, contact angle measurement system, and tensile tester. 


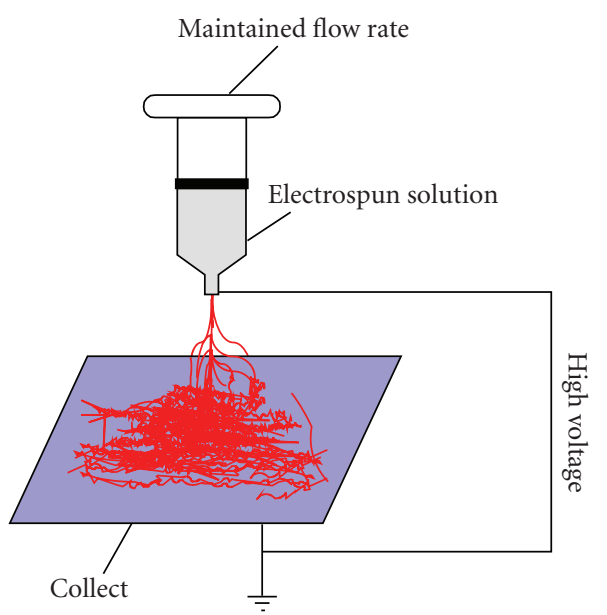

FIGURE 1: Schematic of the general electrospinning setup.

\section{Materials and Methods}

2.1. Materials. $\mathcal{E}$-Caprolactone (CL) was obtained from Acros Organics. L-Lactide (L-LA) was purified by recrystallization with ethyl acetate. PEO was used as received (Changchun Dadi Fine Chemical Co., Ltd, P. R. China). Nano-HA [29] and random copolymer of PLCL [30] [L$\mathrm{LA} / \mathcal{\varepsilon}-\mathrm{CL}=6: 4(\mathrm{~mol} / \mathrm{mol})]\left(M_{\mathrm{w}}=240,000 \mathrm{~g} / \mathrm{mol}\right)$ were produced by ourselves. Dichloromethane, chloroform, and $\mathrm{N}$, $\mathrm{N}$-dimethylformamide were used without further purification.

2.2. Solvents and Electrospinning. PLCL solutions were prepared by dissolving $1.2 \mathrm{~g}$ of PLCL in $20 \mathrm{~mL}$ of chloroform/dichloromethane/DMF (5/3/2, v/v/v) mixed solvent and stirred for 6 hours. Then typically $0.08 \mathrm{~g}$ of PEO and $0.006 \mathrm{~g}$ of HA were mixed into PLCL solution sequentially. The mixed solutions were stirred for additional 12 hours and finally vibrated by supersonic oscillator for 10 minutes. The $20 \mathrm{~mL}$ of solution were loaded into a $20 \mathrm{~mL}$ syringe (the needle diameter was $0.9 \mathrm{~mm}$ ) and injected into the $\mathrm{Al}$ collector under a high field strength $(12 \mathrm{kV} / 18 \mathrm{~cm})$ at an injection rate of $3 \mathrm{~mL} / \mathrm{h}$. The schematic of the general electrospinning setup was shown in Figure 1.

2.3. Composite Nanofiber Morphology. The morphology of $\mathrm{PLCL} / \mathrm{PEO} / \mathrm{HA}$ fibers was observed with an S-2360N scanning electron microscope (SEM) (Hitachi, Japan) at an accelerating voltage of $20 \mathrm{kV}$ and H-600 TEM (Hitachi, Japan) at an accelerating voltage of $75 \mathrm{kV}$. Electrospun fibers were sputter-coated with gold prior to SEM analysis. TEM samples were loaded on copper grids. The average diameter of electrospun fibers was determined by measuring the diameters of nanofibers at 70 different points.

2.4. Surface Tension of the Solution and Surface Contact Angle of Membrane. Surface tension of the solution and surface contact angle of the membrane were measured by a contact angle measurement system (OCA, Dataphysics,
TABle 1: The contents of PLCL, PEO, and HA in electrospun solutions, respectively, and the surface tension of these solutions and the average diameter of composite fiber.

\begin{tabular}{lccc}
\hline Sample & $\begin{array}{c}\text { PLCL/PEO/HA } \\
\text { concentration } \\
(\%, \mathrm{~g} / \mathrm{mL})\end{array}$ & $\begin{array}{c}\text { Average fiber } \\
\text { diameter }(\mu \mathrm{m})^{*}\end{array}$ & $\begin{array}{c}\text { Surface tension } \\
(\mathrm{mN} / \mathrm{m})^{* *}\end{array}$ \\
\hline 1 & $6 / 0 / 0$ & $0.90 \pm 0.25$ & $32.42 \pm 0.50$ \\
2 & $6 / 0.2 / 0.03$ & $1.28 \pm 0.29$ & $31.75 \pm 0.75$ \\
3 & $6 / 0.3 / 0.03$ & $1.35 \pm 0.43$ & $31.52 \pm 0.38$ \\
4 & $6 / 0.4 / 0.03$ & $2.09 \pm 0.28$ & $31.47 \pm 0.45$ \\
5 & $6 / 0.5 / 0.03$ & $1.45 \pm 0.71$ & $31.46 \pm 0.50$ \\
6 & $6 / 0.6 / 0.03$ & $1.46 \pm 0.22$ & $26.55 \pm 0.71$ \\
7 & $6 / 0.4 / 0.01$ & $1.19 \pm 0.22$ & - \\
8 & $6 / 0.4 / 0.05$ & $1.04 \pm 0.14$ & - \\
9 & $6 / 0.4 / 0.07$ & $0.85 \pm 0.19$ & - \\
10 & $6 / 0.4 / 0.1$ & $1.53 \pm 0.22$ & - \\
\hline
\end{tabular}

*The data are representative of seventy samples and expressed as mean \pm $\mathrm{SD}(n=70)$.

**The data are representative of five samples and expressed as mean $\pm \mathrm{SD}$ $(n=5)$.

Germany). A single drop of distilled water was dropped on the membrane samples.

2.5. Mechanical Properties of Membrane. Mechanical properties of electrospun PLCL/PEO/HA membranes were measured using a CMT6104 tensile tester (TUV, Germany) at a cross-head speed of $10 \mathrm{~mm} / \mathrm{min}$ at room temperature. All samples were $80 \times 10 \mathrm{~mm}^{2}$ with a thickness of $50-$ $120 \mu \mathrm{m}$. The tensile strength and elongation at break were both averaged over three samples.

\section{Results and Discussion}

3.1. Morphology of Composite Nanofibers. A series of PLCL/PEO/HA composite fibrous membranes were prepared by electrospinning technology for investigating the effects of PEO and HA contents on the performance of the composite membrane. The concentrations of PEO or HA are shown in Table 1. The morphology of nanofibers is shown by SEM images in Figures 2 and 3. And the inserted images show the diameter distributions of composite fiber. Continuous nanofibers were successfully obtained when the PEO content was varied from 0.2 to $0.6 \%$ and the contents of PLCL and HA were $6 \%$ and $0.03 \%$, respectively. The fibers containing $0.4 \%$ of PEO were more uniform than other fibers. The average fiber diameter was $2.09 \pm$ $0.28 \mu \mathrm{m}$ (Table 1 and Figure $4(\mathrm{a})$ ). It is known that fiber morphology was influenced by solution properties [31, 32] such as viscosity, surface tension and conductivity, and electrospinning parameters. In this investigation, the conductivity of solution would not change largely because of the nonconducting solution and the electrospinning parameters were the same. So this is due to the variety of viscosity and surface tension of electrospun solution with different PEO concentration. The surface tension also 


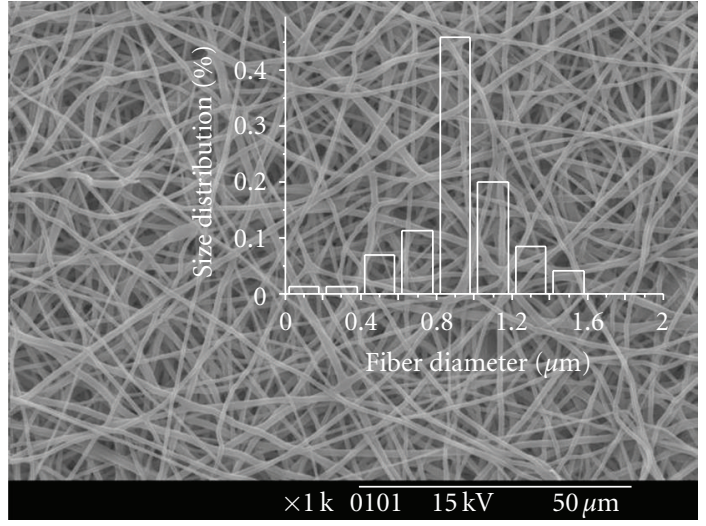

(a)

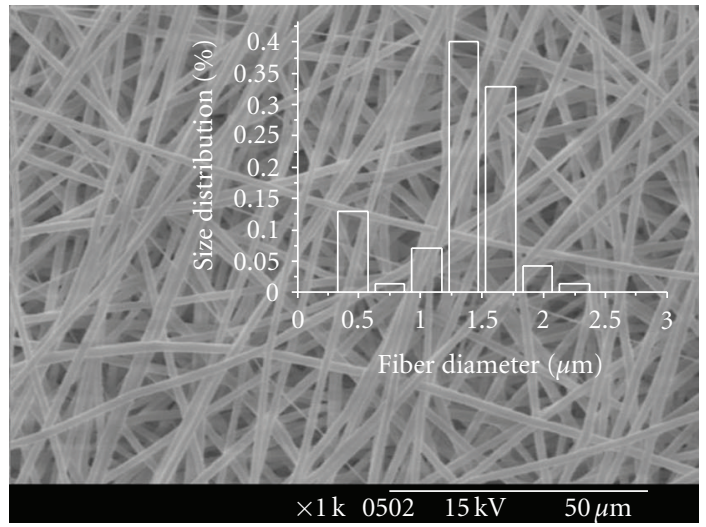

(c)

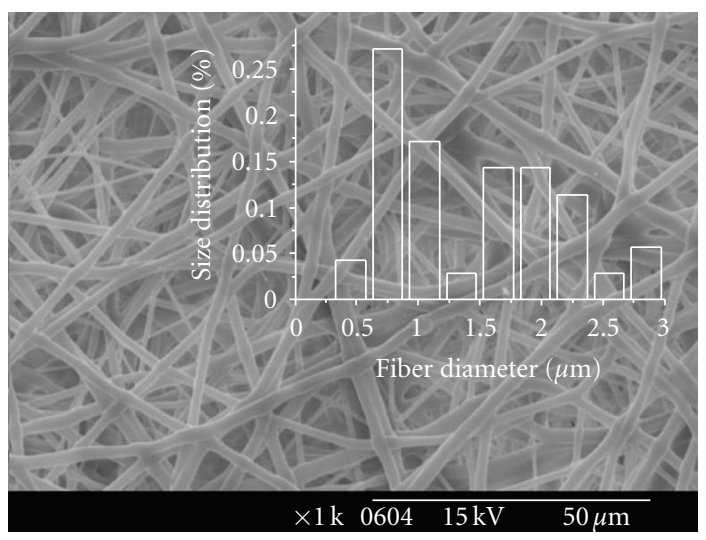

(e)

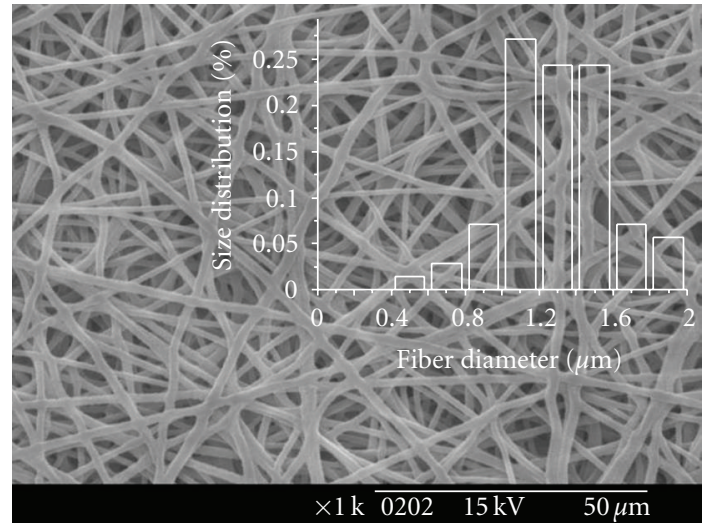

(b)

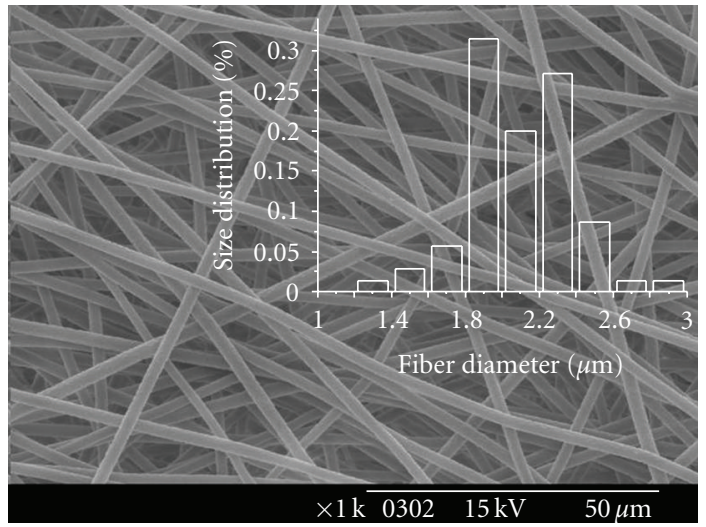

(d)

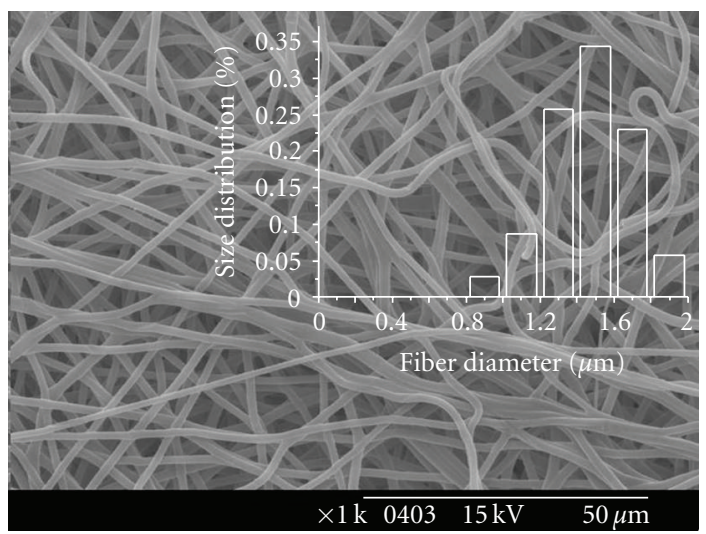

(f)

Figure 2: SEM images of PLCL/PEO/HA nanofibers: (a) pure PLCL; (b)-(f) PLCL and HA contents were fixed at 6\% and $0.03 \%$, respectively, (b) $0.2 \%$ PEO; (c) $0.3 \%$ PEO; (d) $0.4 \%$ PEO; (e) $0.5 \%$ PEO; (f) $0.6 \%$ PEO. The insets show the fiber size distributions

changed slightly (Table 1) while viscosity increased obviously with the increase of PEO concentration. Generally, proper $\mathrm{PEO}$ can improve the spinnability [33]. However, excess PEO may result in the excessive entanglement of PLCL and PEO which has negative effect on forming fibers. Obviously, the optimal concentrations of PLCL and PEO are $6 \%$ and $0.4 \%$, respectively, in the range of this investigation.

So the contents of PLCL and PEO were fixed at $6 \%$ and $0.4 \%$, respectively, while the HA content was varied from 0.01 to $0.1 \%$. These fibers were all uniform (Figure 3 ). HA with nanoscale $(0.01-0.1 \%)$ did not have obvious an effect on fiber diameter (Figure 4 (b)) and morphology of membrane. With the decrease of HA and PEO contents, the dispersion of HA was improved as shown in Figure 5 (the dark areas). Low HA content can reduce the aggregation of HA nanoparticles and less PEO content can reduce the viscosity of the solution which are both beneficial for the dispersion of HA. 


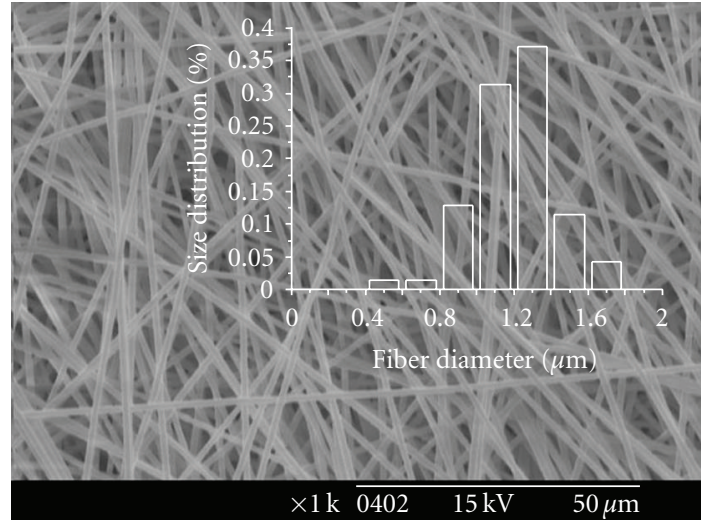

(a)

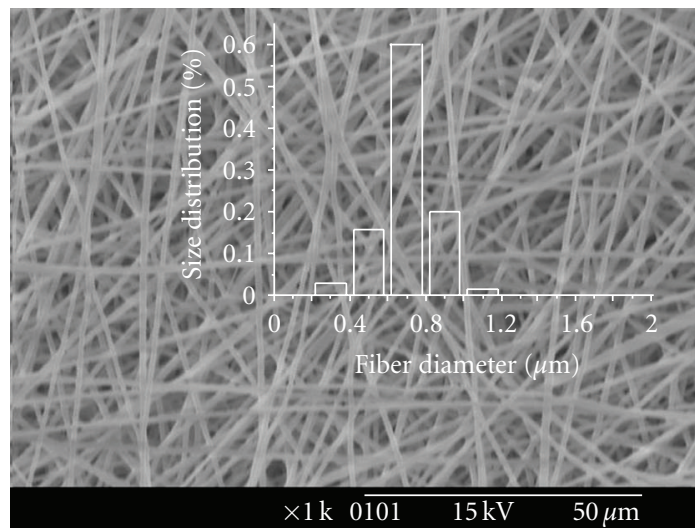

(c)

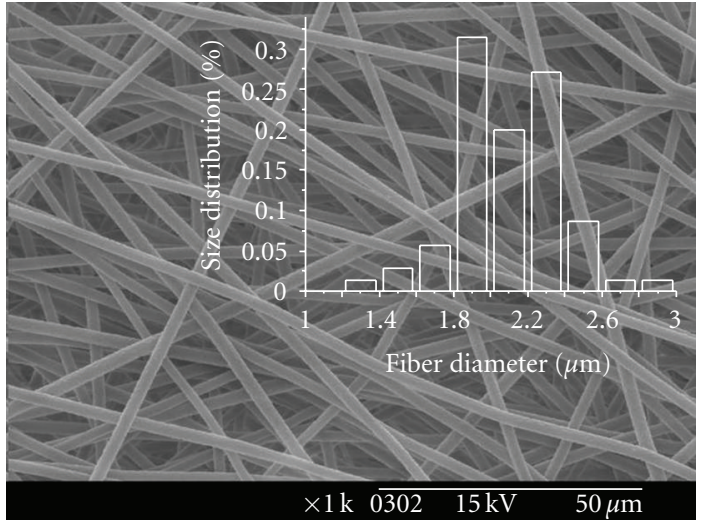

(b)

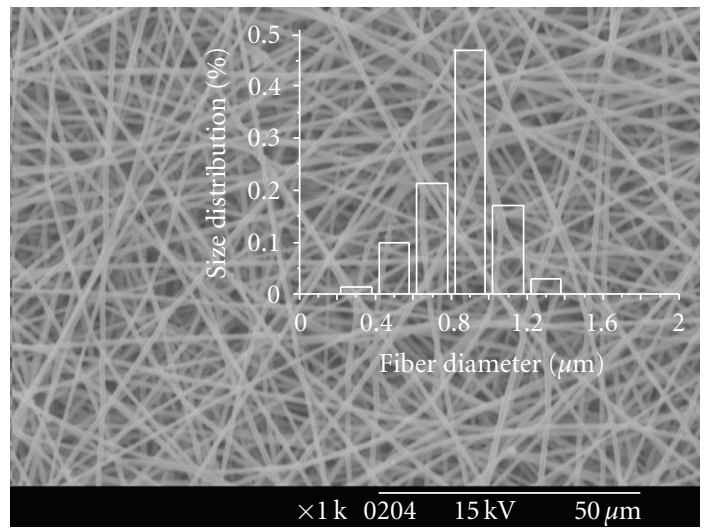

(d)

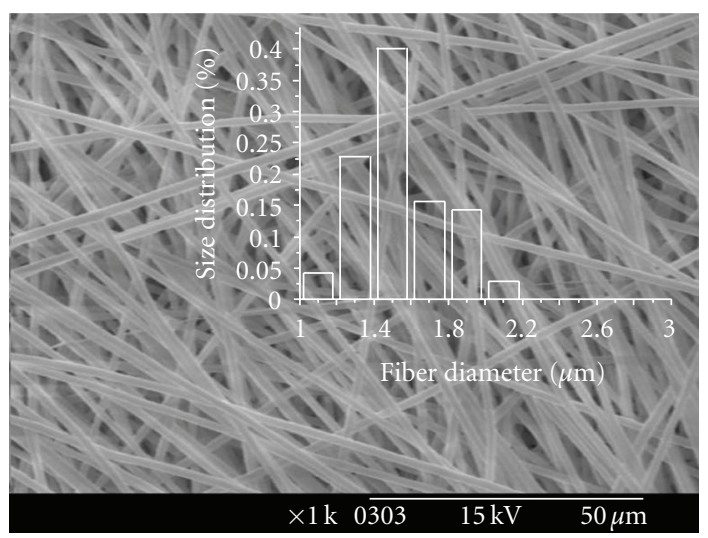

(e)

Figure 3: SEM images of PLCL/PEO/HA nanofibers: (a)-(e) PLCL and PEO contents were fixed at 6\% and 0.4\%, respectively, (a) $0.01 \%$ HA; (b) $0.03 \% \mathrm{HA}$; (c) $0.05 \% \mathrm{HA}$; (d) $0.07 \% \mathrm{HA}$; (e) $0.1 \% \mathrm{HA}$. The insets show the fiber size distributions.

3.2. Water Permeability. Good hydrophilicity is beneficial for the biocompatibility and flowing of nutrition liquid in vivo. PEO is a kind of hydrophilic polymer, so the membranes containing PEO exhibit better hydrophilicity than pure PLCL membrane (Table 2 and Figure 6). Generally, larger fibers result in larger pore size membrane. So a membrane with $0.4 \% \mathrm{PEO}$ and $0.03 \% \mathrm{HA}$ has the better water permeability than others because of its larger and more uniform fibers.
3.3. Mechanical Properties. The relationship between tensile properties and PEO or HA content in PLCL/PEO/HA nanofibrous membranes is shown in Table 2, Figures 7 and 8. The elongation at break increased below $0.3 \%$ of PEO content, which may be attributed to the good toughness of PEO, and decreased afterwards, which may be because the excess PEO has negative effects on fiber arrangement and bonding as shown in Figure 2. So the toughness of nanofibrous membranes is reduced with excess 


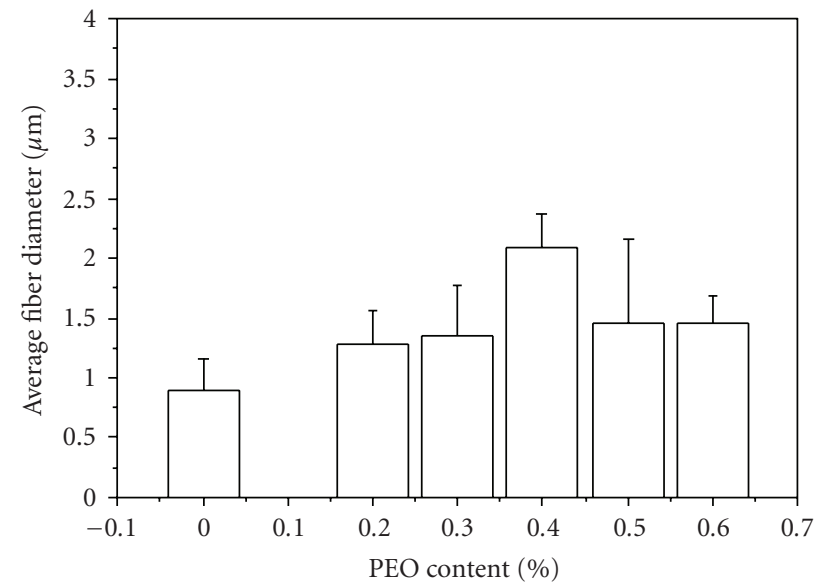

(a)

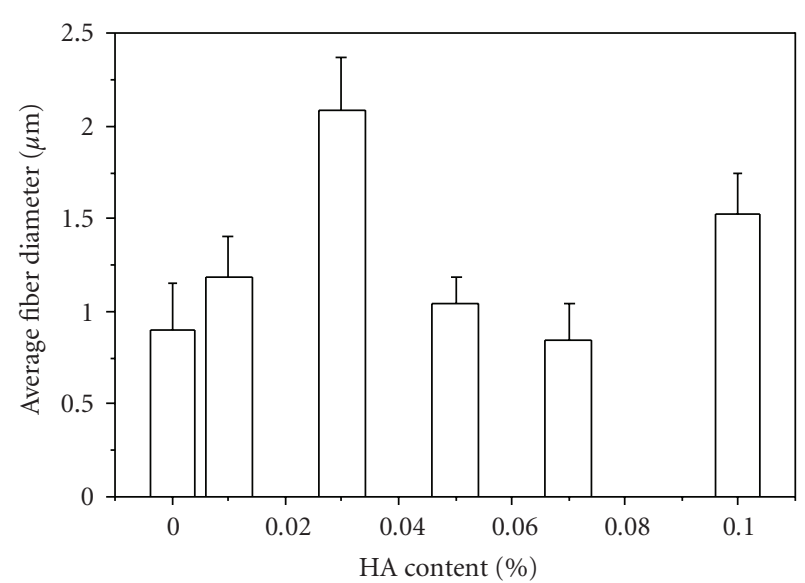

(b)

FIGURe 4: The effect of PEO and HA contents on average fiber diameter. (a) The effect of PEO content on average fiber diameter; (b) the effect of HA content on average fiber diameter.

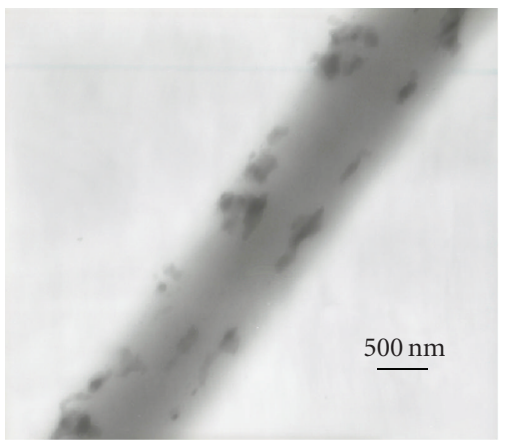

(a)

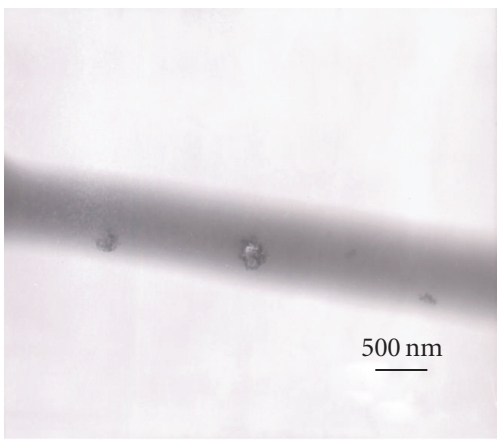

(b)

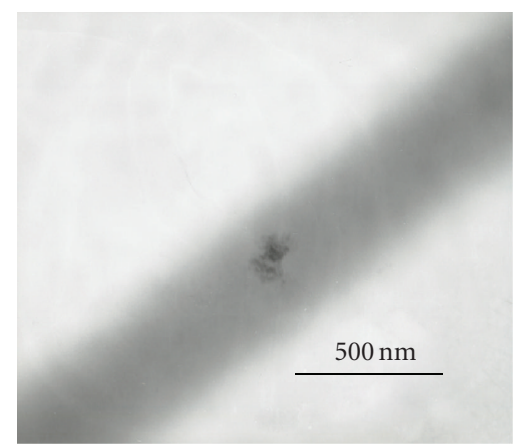

(c)

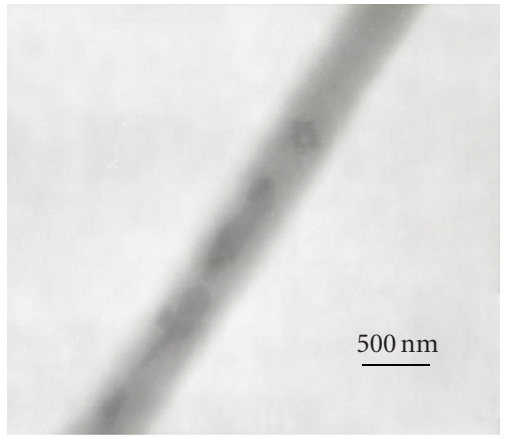

(d)

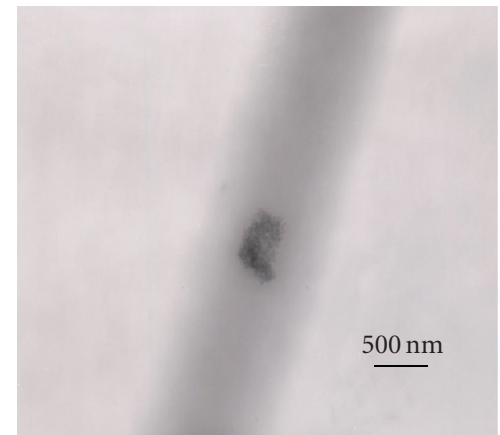

(e)

Figure 5: TEM images of the electrospun PLCL/PEO/HA nanocomposite fibers. (a) PLCL/PEO/HA: 6/0.4/0.01; (b) PLCL/PEO/HA: 6/0.4/0.03; (c) PLCL/PEO/HA: 6/0.4/0.07; (d) PLCL/PEO/HA: 6/0.2/0.03; (e) PLCL/PEO/HA: 6/0.6/0.03.
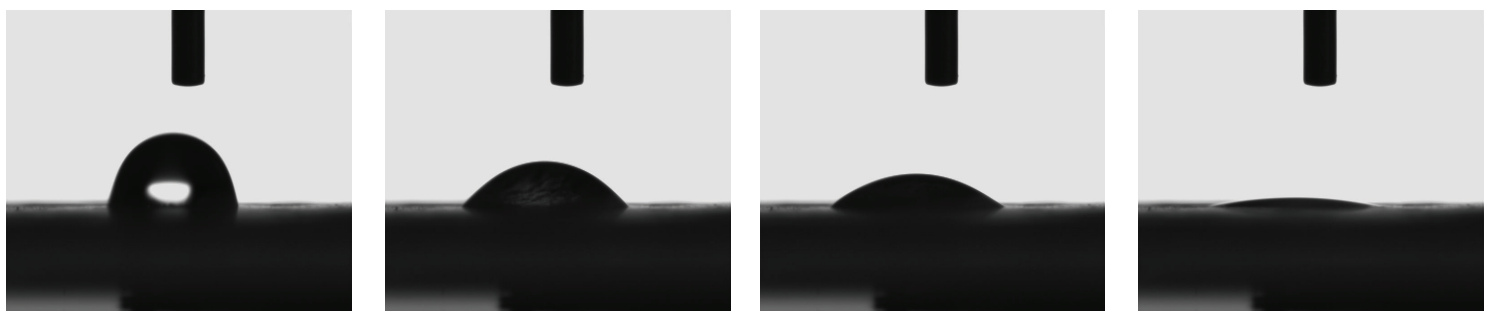

FIgure 6: The change of contact angles of the PLCL/PEO/HA (6/0.4/0.03) composite fibrous. 
TABLE 2: Mechanical properties and contact angles of the PLCL/PEO/HA composite fibrous membranes.

\begin{tabular}{|c|c|c|c|c|}
\hline $\begin{array}{l}\text { Materails and their } \\
\text { concentration }(\mathrm{g} / \mathrm{mL})\end{array}$ & $\begin{array}{l}\text { Tensile strength } \\
(\mathrm{MPa})^{*}\end{array}$ & $\begin{array}{l}\text { Elongation at break } \\
(\%)^{*}\end{array}$ & $\begin{array}{l}\text { Contact angle in } 5 \text { minutes } \\
\left({ }^{\circ} \mathrm{C}\right)\end{array}$ & $\begin{array}{l}\text { Contact angle in } 5 \text { seconds } \\
\left({ }^{\circ} \mathrm{C}\right)\end{array}$ \\
\hline PLCL (6) & $9.88 \pm 0.64$ & $1.85 \pm 0.43$ & 130.0 & - \\
\hline $\begin{array}{l}\mathrm{PLCL} / \mathrm{PEO} / \mathrm{HA} \\
(6 / 0.3 / 0.03)\end{array}$ & $10.64 \pm 0.38$ & $3.53 \pm 0.35$ & 60.9 & - \\
\hline $\begin{array}{l}\mathrm{PLCL} / \mathrm{PEO} / \mathrm{HA} \\
(6 / 0.4 / 0.03)\end{array}$ & $13.97 \pm 0.74$ & $2.61 \pm 0.12$ & 0 & 0 \\
\hline $\begin{array}{l}\mathrm{PLCL} / \mathrm{PEO} / \mathrm{HA} \\
(6 / 0.5 / 0.03)\end{array}$ & $17.19 \pm 0.32$ & $2.79 \pm 1.20$ & 0 & 73.5 \\
\hline $\begin{array}{l}\mathrm{PLCL} / \mathrm{PEO} / \mathrm{HA} \\
(6 / 0.6 / 0.03)\end{array}$ & $10.47 \pm 1.24$ & $2.21 \pm 0.46$ & 32.9 & - \\
\hline $\begin{array}{l}\mathrm{PLCL} / \mathrm{PEO} / \mathrm{HA} \\
(6 / 0.4 / 0.01)\end{array}$ & $8.83 \pm 0.28$ & $2.08 \pm 0.02$ & 0 & 37.5 \\
\hline $\begin{array}{l}\mathrm{PLCL} / \mathrm{PEO} / \mathrm{HA} \\
(6 / 0.4 / 0.03)\end{array}$ & $13.97 \pm 0.74$ & $2.61 \pm 0.12$ & 0 & 0 \\
\hline $\begin{array}{l}\mathrm{PLCL} / \mathrm{PEO} / \mathrm{HA} \\
(6 / 0.4 / 0.05)\end{array}$ & $12.50 \pm 1.03$ & $2.00 \pm 0.15$ & 0 & 109.1 \\
\hline $\begin{array}{l}\mathrm{PLCL} / \mathrm{PEO} / \mathrm{HA} \\
(6 / 0.4 / 0.1)\end{array}$ & $8.22 \pm 1.01$ & $2.24 \pm 0.22$ & 129.2 & - \\
\hline
\end{tabular}

*The data are representative of three samples and expressed as mean $\pm \mathrm{SD}(n=3)$.

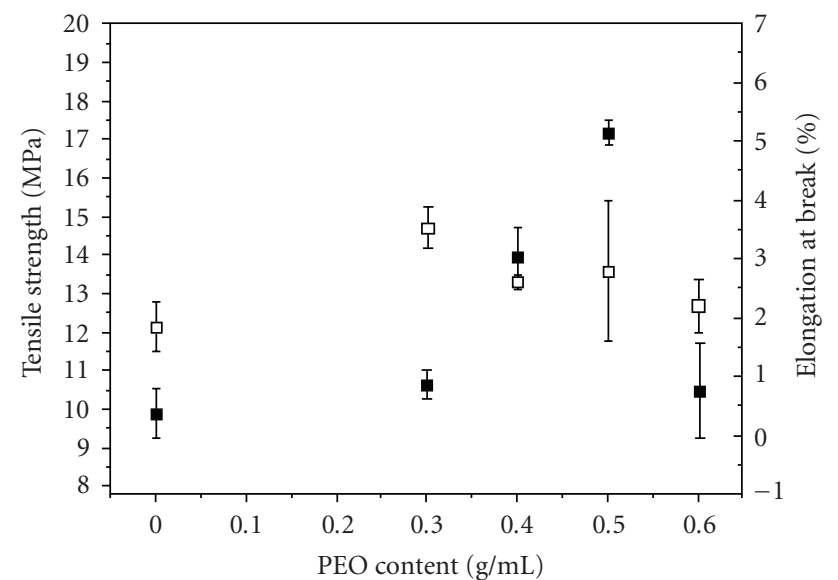

- Tensile strength

․ Elongation at break

FIGURE 7: The effect of PEO content on mechanical properties of composite fibrous membranes.

PEO. Moreover, the tensile strength increases when the content of HA is below $0.03 \%$ and increased afterwards. Obviously, the presence of HA with suitable content can improve the mechanical properties of the membrane. However, excess HA hinders the formation of fibers because of their agglomerate in some extent and produce defects in fibers which lead to the decrease of tensile strength (Figure 5).

\section{Conclusion}

PLCL/PEO/HA nanofibrous membranes were prepared by electrospinning. Addition of PEO and HA with suitable content to PLCL solution can improve the GBRMS's hydrophilic

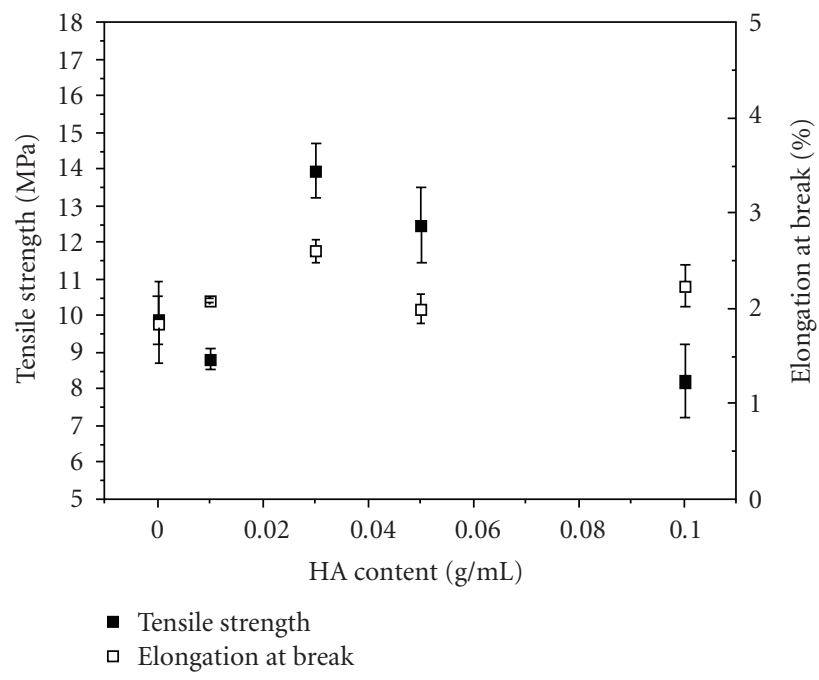

FIGURE 8: The effect of HA content on mechanical properties of composite fibrous membranes.

and mechanical properties effectively. According to the SEM images, more uniform fibers and larger average fiber diameter were obtained when the contents of PEO and HA were $0.4 \%$ and $0.03 \%$, respectively. So the composite membrane in this constitute had the best water permeability. Furthermore, the mechanical properties of membrane were improved by adding HA nanocrystals. And the largest tensile strength of nanofibrous membrane can be obtained with $0.5 \%$ content of PEO and $0.03 \%$ content of HA.

\section{Acknowledgments}

This work was supported by National Natural Science Foundation of China (project number: 30800230/C100202) 
and the project of Nano Science and Technology of Shanghai, China. (project number: 0852nm03600).

\section{References}

[1] N. P. Lang, C. H. Hämmerle, U. Brägger, B. Lehmann, and S. R. Nyman, "Guided tissue regeneration in jawbone defects prior to implant placement," Clinical Oral Implants Research, vol. 5, no. 2, pp. 92-97, 1994.

[2] C. Tinti, G. Vincenzi, P. Cortellini, G. Pini Prato, and C. Clauser, "Guided tissue regeneration in the treatment of human facial recession. A 12-case report," Journal of Periodontology, vol. 63, no. 6, pp. 554-560, 1992.

[3] H. M. Powell and S. T. Boyce, "Fiber density of electrospun gelatin scaffolds regulates morphogenesis of dermalepidermal skin substitutes," Journal of Biomedical Materials Research Part A, vol. 84, no. 4, pp. 1078-1086, 2007.

[4] T. Takata, H.-L. Wang, and M. Miyauchi, "Attachment, proliferation and differentiation of periodontal ligament cells on various guided tissue regeneration membranes," Journal of Periodontal Research, vol. 36, no. 5, pp. 322-327, 2001.

[5] R. G. Caffesse, C. E. Nasjleti, E. C. Morrison, and R. Sanchez, "Guided tissue regeneration: comparison of bioabsorbable and non-bioabsorbable membranes. Histologic and histometric study in dogs," Journal of Periodontology, vol. 65, no. 6, pp. 583-591, 1994.

[6] A. K. Schlegel, H. Möhler, F. Busch, and A. Mehl, "Preclinical and clinical studies of a collagen membrane (Bio-Gide $\left.{ }^{\circledR}\right)$," Biomaterials, vol. 18, no. 7, pp. 535-538, 1997.

[7] A. Stavropoulos, A. Sculean, and T. Karring, "GTR treatment of intrabony defects with PLA/PGA copolymer or collagen bioresorbable membranes in combination with deproteinized bovine bone (Bio-Oss)," Clinical Oral Investigations, vol. 8, no. 4, pp. 226-232, 2004.

[8] J.-H. Song, H.-E. Kim, and H.-W. Kim, "Production of electrospun gelatin nanofiber by water-based co-solvent approach," Journal of Materials Science: Materials in Medicine, vol. 19, no. 1, pp. 95-102, 2008.

[9] P. Pellen-Mussi, P. Fravalo, M. Guigand, and M. BonnaureMallet, "Evaluation of cellular proliferation on collagenous membranes," Journal of Biomedical Materials Research, vol. 36, no. 3, pp. 331-336, 1997.

[10] S. M. Kuo, S. J. Chang, T. W. Chen, and T. C. Kuan, "Guided tissue regeneration for using a chitosan membrane: an experimental study in rats," Journal of Biomedical Materials Research Part A, vol. 76, no. 2, pp. 408-415, 2006.

[11] U. S. Sajeev, K. A. Anand, D. Menon, and S. Nair, "Control of nanostructures in PVA, PVA/chitosan blends and PCL through electrospinning," Bulletin of Materials Science, vol. 31, no. 3, pp. 343-351, 2008.

[12] H. W. Kim, J. H. Song, and H. E. Kim, "Nanofiber genenration of gelation-hydroxyapatite biomimetics for guided tissue regeneration," Advanced Functional Materials, vol. 15, pp. 1988-1994, 2005.

[13] E. Milella, G. Barra, P. A. Ramires, G. Leo, P. Aversa, and A. Romito, "Poly(L-lactide)acid/alginate composite membranes for guided tissue regeneration," Journal of Biomedical Materials Research, vol. 57, no. 2, pp. 248-257, 2001.

[14] Z.-M. Huang, Y. Zhang, and S. Ramakrishna, "Double-layered composite nanofibers and their mechanical performance," Journal of Polymer Science, Part B, vol. 43, no. 20, pp. 28522861, 2005.
[15] K. Fujihara, M. Kotaki, and S. Ramakrishna, "Guided bone regeneration membrane made of polycaprolactone/calcium carbonate composite nano-fibers," Biomaterials, vol. 26, no. 19, pp. 4139-4147, 2005.

[16] X. Xu, X. Chen, A. Liu, Z. Hong, and X. Jing, "Electrospun poly(l-lactide)-grafted hydroxyapatite/poly(l-lactide) nanocomposite fibers," European Polymer Journal, vol. 43, no. 8, pp. 3187-3196, 2007.

[17] I. K. Kwon and T. Matsuda, "Co-electrospun nanofiber fabrics of poly(L-lactide-co- $\varepsilon$-caprolactone) with type I collagen or heparin," Biomacromolecules, vol. 6, pp. 2096-2105, 2005.

[18] J. H. Kim, P.-H. Choung, I. Y. Kim, et al., "Electrospun nanofibers composed of poly( $\varepsilon$-caprolactone) and polyethylenimine for tissue engineering applications," Materials Science and Engineering C, vol. 29, no. 5, pp. 1725-1731, 2009.

[19] Y. Ueyama, K. Ishikawa, T. Mano, et al., "Usefulness as guided bone regeneration membrane of the alginate membrane," Biomaterials, vol. 23, no. 9, pp. 2027-2033, 2002.

[20] G. R. H. Owen, J. Jackson, B. Chehroudi, H. Burt, and D. M. Brunette, "A PLGA membrane controlling cell behaviour for promoting tissue regeneration," Biomaterials, vol. 26, no. 35, pp. 7447-7456, 2005.

[21] M. Kikuchi, Y. Koyama, T. Yamada, et al., "Development of guided bone regeneration membrane composed of $\beta$ tricalcium phosphate and poly(L-lactide-co-glycolide-co- $\varepsilon$ caprolactone) composites," Biomaterials, vol. 25, no. 28, pp. 5979-5986, 2004.

[22] S. Liao, W. Wang, M. Uo, et al., "A three-layered nanocarbonated hydroxyapatite/collagen/PLGA composite membrane for guided tissue regeneration," Biomaterials, vol. 26, no. 36, pp. 7564-7571, 2005.

[23] Y. J. Park, K. H. Nam, S. J. Ha, C. M. Pai, C. P. Chung, and S. J. Lee, "Porous poly(L-lactide) membranes for guided tissue regeneration and controlled drug delivery: membrane fabrication and characterization," Journal of Controlled Release, vol. 43, no. 2-3, pp. 151-160, 1997.

[24] K. S. Tiaw, S. H. Teoh, R. Chen, and M. H. Hong, "Processing methods of ultrathin poly( $\varepsilon$-caprolactone) films for tissue engineering applications," Biomacromolecules, vol. 8, no. 3, pp. 807-816, 2007.

[25] J. Lannutti, D. Reneker, T. Ma, D. Tomasko, and D. Farson, "Electrospinning for tissue engineering scaffolds," Materials Science and Engineering C, vol. 27, no. 3, pp. 504-509, 2007.

[26] Q. P. Pham, U. Sharma, and A. G. Mikos, "Electrospun poly ( $\varepsilon$ caprolactone) microfiber and multilayer nanofiber/microfiber scaffolds: characterization of scaffolds and measurement of cellular infiltration," Biomacromolecules, vol. 7, no. 10, pp. 2796-2805, 2006.

[27] K. Fujihara, M. Kotaki, and S. Ramakrishna, "Guided bone regeneration membrane made of polycaprolactone/calcium carbonate composite nano-fibers," Biomaterials, vol. 26, no. 19, pp. 4139-4147, 2005.

[28] H.-W. Kim, H.-H. Lee, and J. C. Knowles, "Electrospinning biomedical nanocomposite fibers of hydroxyapaite/ poly(lactic acid) for bone regeneration," Journal of Biomedical Materials Research, Part A, vol. 79, no. 3, pp. 643-649, 2006.

[29] G. Shuying, Z. Hui, R. Jie, and Z. Xinyu, "Sol-gel synthesis and characterisation of nano-sized hydroxyapatite powders and hydroxyapatite/ poly(D,L-lactide-co-glycolide) composite scaffolds," Polymers \& Polymer Composites, vol. 15, no. 2, pp. 137-144, 2007. 
[30] K. Garkhal, S. Verma, S. Jonnalagadda, and N. Kumar, "Fast degradable poly(L-lactide-co-E-caprolactone) microspheres for tissue engineering: synthesis, characterization, and degradation behavior," Journal of Polymer Science, Part A, vol. 45, no. 13, pp. 2755-2764, 2007.

[31] S. L. Shenoy, W. D. Bates, H. L. Frisch, and G. E. Wnek, "Role of chain entanglements on fiber formation during electrospinning of polymer solutions: good solvent, nonspecific polymer-polymer interaction limit," Polymer, vol. 46, no. 10, pp. 3372-3384, 2005.

[32] J. H. Yu, S. V. Fridrikh, and G. C. Rutledge, "The role of elasticity in the formation of electrospun fibers," Polymer, vol. 47, no. 13, pp. 4789-4797, 2006.

[33] B. Duan, C. Dong, X. Yuan, and K. Yao, "Electrospinning of chitosan solutions in acetic acid with poly(ethylene oxide)," Journal of Biomaterials Science, Polymer Edition, vol. 15, no. 6, pp. 797-811, 2004. 

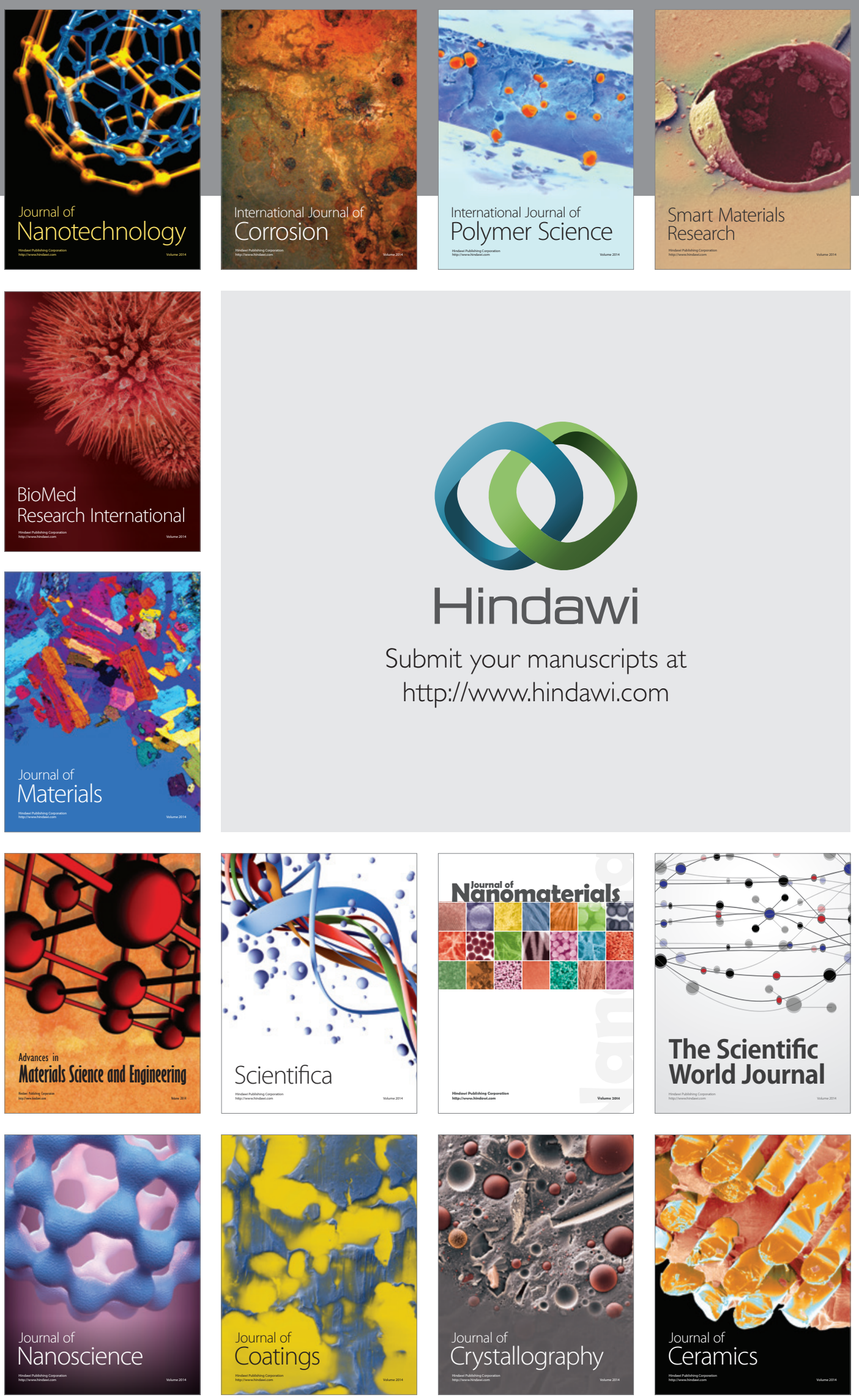

The Scientific World Journal

Submit your manuscripts at

http://www.hindawi.com

\section{World Journal}

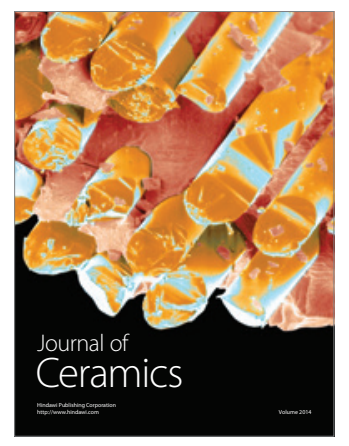

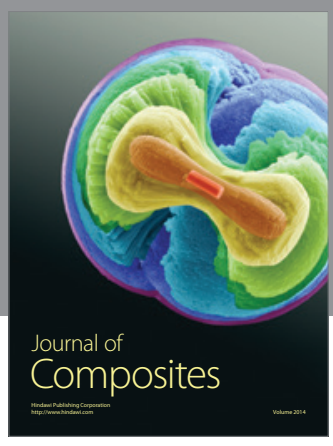
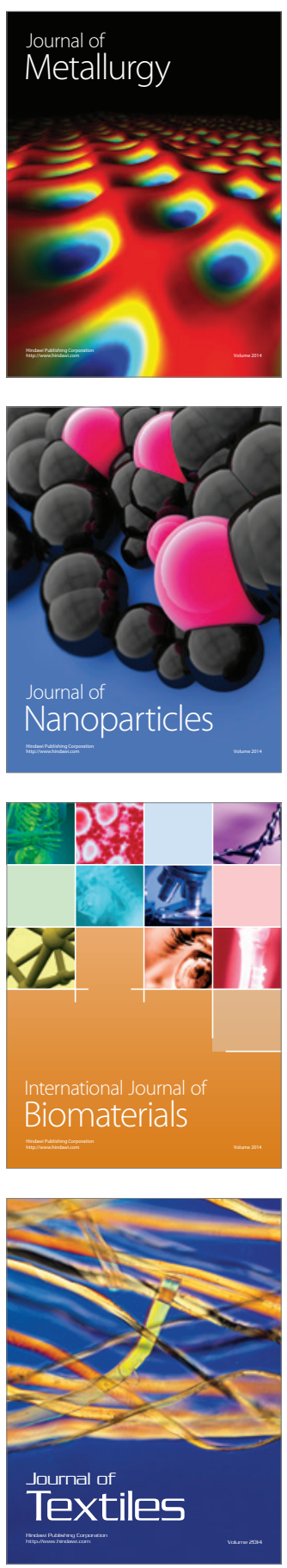